\title{
Saf Alüminyuma Uygulanan İki Așamalı Anodik Oksidasyon İşleminde Por Genişletme Süresinin Oksit Porlar Üzerindeki Etkilerinin İncelenmesi
}

\author{
Halil Yilmaz ${ }^{1 *}$, Mustafa Kocabaş ${ }^{2}$ \\ ${ }^{1}$ Makine ve Metal Teknolojileri Bölümü, Muş Alparslan Üniversitesi, Muş, Türkiye (ORCID: 0000-0003-3585-0665) \\ ${ }^{2}$ Metalurji ve Malzeme Mühendisliği Bölümü, Konya Teknik Üniversitesi, Konya, Türkiye (ORCID: 0000-0003-2179-5183)
}

(Illk Geliş Tarihi 31 Ağustos 2019 ve Kabul Tarihi 27 Eylül 2019)

(DOI: 10.31590/ejosat.613555)

ATIF/REFERENCE: Yılmaz, H. \& Kocabaş, M. (2019). Saf Alüminyuma Uygulanan İki Aşamalı Anodik Oksidasyon İşleminde Por Genişletme Süresinin Oksit Porlar Üzerindeki Etkilerinin İncelenmesi. Avrupa Bilim ve Teknoloji Dergisi, (17), 38-44.

\section{Öz}

Anodik oksidasyon işlemi alüminyum, tantalyum, titanyum, molibden vb. metal ve alaşımlarının yüzey özelliklerini geliştirmek ve böylece bu metallerden üretilen parçaların servis ömürlerini arttırmak için yaygın bir şekilde kullanılan bir yüzey işlemidir. Çok farklı türlerde ve koşullarda yapılan anodik oksidasyon işleminin bir türü de iki aşamalı anodik oksidasyon işlemidir. İki aşamalı anodik oksidasyon işlemi, alüminyum gibi uygun bir metal yüzeyinde sürekli bir tabaka oluşturarak korozyon direncini arttırma gibi birçok yüzey özelliğini geliştiren bir işlemdir. Tek aşamalı anodik oksidasyona göre daha düzenli bir por dizilimine sahip olan iki aşamalı anodik oksidasyon işleminde, nanoteknoloji uygulamaları çok hızlı bir gelişim göstermiş ve bununla beraber çeşitli nano-tüpler ve nano-tellerin potansiyel üretimleri yapılmaktadır. Bu çalışmada, saf alüminyum yüzeyinde iki aşamalı potansiyostatik anodik oksidasyon işlemi incelenmiştir. Bu amaçla elektrolitik olarak parlatılan numuneler $0,3 \mathrm{M}$ oksalik $\left(\mathrm{C}_{2} \mathrm{H}_{2} \mathrm{O}_{4}\right)$ asit çözeltisinde $40 \mathrm{~V}$ sabit gerilim değerinde farklı sürelerde anodize edilen numuneler $0,1 \mathrm{M}$ fosforik $\left(\mathrm{H}_{3} \mathrm{PO}_{4}\right)$ asit çözeltisinde por genişletme işlemine tabi tutulmuştur. Sabit gerilim değerinde yapılan anodik oksidasyon işlemleri sırasında elde edilen akım yoğunluğu süre grafikleri anodik oksidasyon işleminin tekrarlanabilirliği açısından önem arz etmektedir. Farklı sürelerde $(0,30$ ve 60 dakika) yapılan por genişletme işleminden sonra elde edilen gözenekli yapıdaki anodik alüminanın homojenliği ve ortalama por çapları gibi özellikleri yüzeyden yapılan SEM analizleriyle incelenmiştir. Yapılan incelemeler sonunda artan por genişletme süresine bağlı olarak por dizilimlerinin düzgünleştiği ve por çaplarının arttığı tespit edilmiştir. İşlemlerin arzu edilen şekilde yapılmasına bağlı olarak farklı boyutlara sahip nanotellerin/tüplerin üretimi, istenilen düzgün ve homojen nanoyapılar şeklinde gerçekleştirilebilecektir.

\section{Investigation of the Effects of Pore Widening Times on Oxide Pores on Pure Aluminum in Two-Step Anodic Oxidation Process}

\begin{abstract}
An anodic oxidation process is a commonly used for surface treatment to improve the surface properties of the metals and their alloys such as aluminum, tantalum, titanium, molybdenum etc. and thereby increase the service life of the specimen parts produced from these metals. A type of anodic oxidation process with different types and conditions is made in the two-step anodic oxidation process. The two-step anodic oxidation is a process that improves several surface properties, such as increasing the corrosion resistance by forming a continuous layer on the surface of a suitable metal such as aluminum. In a two-step anodic oxidation process, which has a more regular pore array than one-step anodic oxidation, nanotechnology applications have been rapidly developing and with the
\end{abstract}

\footnotetext{
${ }^{1}$ Sorumlu Yazar: Muş Alparslan Üniversitesi Üniversitesi, Makine ve Metal Teknolojileri Bölümü, Muş, Türkiye, ORCID: 0000-0003-3585-0665, halil.yilmaz@alparslan.edu.tr
} 
potential production of various nano-tubes and nano-wires. In this study, the two-step potentiostatic anodic oxidation process on pure

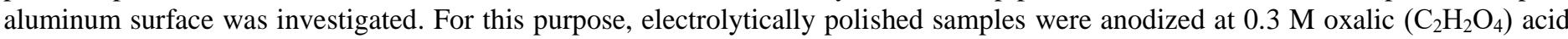
solution at $40 \mathrm{~V}$ constant voltage for different times and were subjected to pore expansion in $0.1 \mathrm{M}_{\text {phosphoric }}\left(\mathrm{H}_{3} \mathrm{PO}_{4}\right)$ acid solution. The current density time graphs obtained during anodic oxidation processes at constant voltages are important for the reproducibility of the anodic oxidation process. The properties of the anodic alumina in the porous structure obtained after pore expansion at different times (0, 30 and 60 minutes) and the average pore diameters were examined by SEM analysis. After the surface investigations, it has been determined that pore arrays become smooth and pore diameters increase depending on an increase in pore widening time. The fabrication of nanowires/tubes with different sizes can be carried in the form of homogeneous nanostructures depending on the desired operation.

Keywords: Pore diameters, Pore widening, Pure aluminum, Two-step anodic oxidation.

\section{Giriş}

Nanoteknoloji en hızlı gelişen bilim dallarından biri olmakla beraber son yıllarda gelişimini sürekli devam ettirmektedir. Nanoteknolojnin uygulama alanlarından biri de nano-tüpler/teller gibi özel yapılı malzemelerin imalatıdır. Bu nano boyuttaki malzemeler, manyetik, fotonik, nano ve mikro elektronik mekanik sistemler (N/MEMS) gibi amaçlar için kullanılan cihazların üretiminde kullanılmaktadır. Nano yapılı malzemelerin sentezi için önerilen çeşitli hazırlama rotaları arasında, gözenekli mebranlar ve şablon destekli yöntemler, nanoteknolojide yaygın olarak kullanılmaktadır (Masuda \& Fukuda, 1995; Zaraska, Sulka, \& Jaskuła, 2010). Düzenli por yapısına sahip anodik alüminyum filmler karakteristik olarak, düzenli altıgen (bal peteği) hücre yapısına sahiptirler ve yüzeye dik olarak büyümektedirler. Malzemelerin bu karakteristik özelliğe sahip olması, üretimi hedeflenen malzemelerin istenilen geometride ve son derece düzenli bir şekilde sentezlenmesi için uygun altlıklar oluşturmaktadır (MonteroMoreno, Sarret, \& Müller, 2007; Zaraska et al., 2010).

Altlık olarak en çok tercih edilen metal olan alüminyumun fiziksel ve kimyasal özelliklerini daha da geliştirmek için oksitlenmiş kalın ve sert tabakaların elde edildiği bazı elektrokimyasal işlemler uygulanmaktadır (Bouchama et al., 2013). Alüminyumun anodik oksidasyon işlemi, korozyon ve aşınmaya karşı koruma sağlamak için bir çözelti içerisinde dış akım uygulanarak alüminyumu okside dönüştürme esasına dayanan bir elektrokimyasal yöntemdir (Bouchama et al., 2013; Konno, Utaka, \& Furuichi, 1996). Anodik alüminyum, alüminyumun mekanik özelliklerini iyileştirmek için anti-korozif veya dekorasyon kaplaması olarak kullanırken, gözenekli anodik alüminyum, kendiliğinden veya bükümlü düzgün silindirik gözenek olarak nanoteknolojide mebran olarak kullanılır (Han \& Shen, 2011). Anodik oksidasyon yöntemi, alüminyumun yanında, magnezyum, niyobyum, titanyum, tungsten ve benzeri metallere de uygulanmaktadır (Moldovan, Bruj, \& Jumate, 2011).

Laboratuvar yapımı gözenekli anodik alümina filmleri genellikle sülfürik, oksalik ve fosforik asit çözeltilerinde kendiliğinden düzenlenen iki aşamalı anodik oksidasyon yöntemiyle hazırlanır (Erdogan, Yuksel, \& Birol, 2012; Li, Müller, Birner, Nielsch, \& Gösele, 1999; Moldovan et al., 2011; Zaraska, Sulka, \& Jaskuła, 2011). Oksalik asit çözeltilerinde yapılan anodik oksidasyon işleminde, yaygın olarak kullanılan sülfürik $\left(\mathrm{H}_{2} \mathrm{SO}_{4}\right)$ asit çözeltilerine göre daha yüksek gerilim değerlerine ihtiyaç duyulmaktadır (Diggle, Downie, \& Goulding, 1969; Sheasby, P., \& Pinner, 2001). Anodik alüminyum oksit, nano boyuttaki malzemeleri üretmek için yapılan ön aşamadır.

Doğal yüzey oksitlerini temizlemek, yüzeyde bulunan intermetalik bileşiklerin sayısını azaltmak ve yüzey pürüzlülüğünü düşürmek için, kimyasal veya mekanik parlatma ve elektrolitik parlatma işlemleri anodik oksidasyon öncesinde yüzeylere uygulanmaktadır (Montero-Moreno, Sarret, \& Müller, 2007). Anodik oksidasyon işleminde elektrolit ve elektrolitin sıcaklığı, gözenek şeklini ve boyutunu etkiler. Düşük sıcaklıklarda yapılan anodik oksidasyon işleminde, kontrollü gözenek oluşumu gözlemlenmektedir. Elektrolit içerisindeki sıcaklık değişimleri, işlem gören numunenin gözeneklilik miktarını belirlemektedir (Ilango, Mutalikdesai, \& Ramasesha, 2016).

Anodik oksidasyon işleminin oksitlerin morfolojisine olan etkileri geniş çapta araştırılmıştır. İlk anodik oksidasyon aşamasında oluşan düzensiz alüminyum oksit tabakasını alüminyumun yüzeyinden uzaklaştırmak için ikinci anodik oksidasyon aşaması öncesinde kullanılan kimyasal dağlama işlemi, anodik oksit şablonlarının morfolojik özellikleri için büyük önem taşımaktadır. Dağlama işlemi için kullanılan en yaygın çözelti fosforik (ağ. \%6) ve kromik $\left(\mathrm{H}_{2} \mathrm{CrO}_{4}\right.$, ağ. \%1,8) asit çözeltisidir ve işlemin sıcaklığı genellikle 45 ila $80{ }^{\circ} \mathrm{C}$ arasında değişlik göstermektedir. Kimyasal dağlama işlemi, alüminyum yüzeyini iyileştirir ve ikinci anodik oksidasyon aşamasından sonra arzu edilen düzenli altıgen nano-gözeneklerin oluşturulmasını sağlamak için alüminyum yüzeyinde yarım küre içbükey bir yüzey oluşturur. Bununla birlikte, kimyasal dağlama parametrelerinin oksit morfolojisi üzerinde ciddi etkileri olmasına rağmen bunun üzerine gerçekleştirilmiş çalışma sayısı sınırlıdır (Erdogan et al., 2012). Sabit akım yoğunluğu veya sabit gerilim değeri ile üretilen poröz oksit filmin gelişimi, süreye karşı akım yoğunluğunun veya gerilim değerinin değişimi izlenerek gözlemlenmektedir. Bu tarz bir inceleme ile deneylerin arzu edilen koşullarda ve standartlarda yapıldığını kontrol edilmektedir (Ma, 2010; Sheasby, P., \& Pinner, 2001; Sulka, 2008).

Küçük boyutlu metalik malzemelerin özellikleri (mekanik, elektriksel ve optik vs.) büyük hacimli benzerlerine göre belirgin özellikleri nedeniyle daha fazla dikkat çekmektedir (Stelmashenko, Walls, Brown, \& Milman, 1993). Çapları $5 \mu$ m'dan daha küçük metalik nanotellerin/sütunların basma ve çekme dayanımları hakkında bir dizi rapor yayımlanmıştır. Tüm durumlarda, nanotellerin/sütunların dayanımı, numune çapı azaldıkça artmaktadır. Bu durum boyut etkisi veya "daha küçük olan daha güçlü”" olgularıyla adlandırılmaktadır. Bu boyut etkisi ilk olarak Uchic vd. (Dimiduk, Uchic, \& Parthasarathy, 2005; Uchic, Dimiduk, 
Florando, \& Nix, 2004) tarafindan Ni nanosütunlar üzerine yapılan deneysel çalışmalar sonucunda görülmüş ve daha sonra yüzey merkezli kübik (ymk) ve hacim merkezli kübik (hmk) yapılı metaller üzerinde yapılan çalışmalar ile yoğunlaşılmıştır (Greer, Oliver, \& Nix, 2005; Kiener, Motz, Schöbert, Jenko, \& Dehm, 2006; Ng \& Ngan, 2008). Küçük numune boyutu, büyük hacimli malzemelerdeki dayanımı kontrol eden özellikleri ortadan kaldırır. Dislokasyonların serbest yüzey ile etkileşimi veya dislokasyon hareketinin kısıtlanması malzemelerin mekanik özelliklerini güçlü bir şekilde etkilemektedir (Greer \& De Hosson, 2011).

$\mathrm{Bu}$ çalışmanın amacı, iki aşamalı anodik oksidasyon işlemi ile yüksek oranda nano gözenekli ve farklı por çaplarına sahip olan oksit şablonunun üretilmesidir. Por genişletme işlemi sayesinde, farklı büyüklüklere ve düzgün dizilime sahip nano yapıların (nanotel/tüp) üretimi gerçekleştirilerek bu malzemelerin basma-çekme testleri sonucunda mekanik özellikleri, deformasyon karakteristikleri ve boyut etkisi üzerine çalışmalar yürütülmesine olanak sağlanacaktır. Nihai ürünün kalitesi ve yapısal özellikleri oksit şablonunun kalitesine bağlıdır. Karakterizasyon çalışmaları her bir işlem sonrasında yapılmış ve uygun koşul belirlendikten sonra bir sonraki adıma geçilmiştir. Üretilen oksitlere ait por çapları ve por dizilimleri, por genişletme işlem süresi ile kontrol edilmiştir.

\section{Materyal ve Metot}

Bu çalışmada, yüksek saflı̆ga sahip $(\% 99,99)$ alüminyum metali kullanılmıştır. Numuneler dikdörtgen plakalar şeklinde $(800 \mathrm{x}$ $400 \times 0,5 \mathrm{~mm}$ ) temin edilmiş, sonrasında deneylerde kullanılmak üzere $50 \times 20 \times 0,5 \mathrm{~mm}$ boyutlarında dikdörtgen levhalar şeklinde kesilmiştir.

Yüzey pürüzlülüğü, yüksek kaliteli anodik oksit katmanları elde edilmesi gerektiğinde dikkate alınması gereken çok önemli bir parametredir. Bu çalışmada gözenekli oksit tabakalarını düzgün bir şekilde elde edebilmek için elektrolitik parlatma yapılmıştır. İlk olarak, dikdörtgen levhalar halinde kesilmiş numuneler etanol ve aseton ile temizlenmiştir. Elektrolitik parlatma işlemi, anodik oksidasyon işlemi öncesinde yüzeyi pürüzsüz ve hatalardan uzaklaştırılmış hale getirecek olan bir işlem olup, \%80 etanol - \%20 perklorik asit (hac.) ç̧̈zeltisi içerisinde gerçekleştirilmiştir. Elektrolitik parlatma işlemi suresince, çözelti sıcaklığ $10{ }^{\circ} \mathrm{C}$ 'nin altında sabit tutulmak kaydıyla her bir numune için sabit sürede (3 dakika) gerçekleştirilmiştir (Bouchama et al., 2013; Iglesias-Rubianes, Skeldon, Thompson, Shimizu, \& Habazaki, 2001; Liu et al., 2009; Thompson, Xu, \& Skeldon, 1987; Zhou et al., 2007). İşlem süresince numuneye sabit $20 \mathrm{~V}$ gerilim uygulanmış ve çözelti ayni zamanda manyetik karıştırıcı yardımıyla karıştırılmışıtır. Numunelerin anot olarak bağlandığı bu sistemde katot malzemesi olarak ise saf alüminyum kullanılmıştır. Numuneler, işlem sonrasında çıplak gözle görülecek şekilde parlamış ve ayna parlaklığı (mirror-like) görüntüsüne kavuşmuştur.

Anodik oksidasyonun ilk aşamasında parlatılmış alüminyum numuneleri, 0,3 M oksalik asit çözeltisi içerisinde $40 \mathrm{~V}$ sabit bir gerilim ve oda sicaklı̆ğında 10 saat boyunca anodize edilmiştir. İkinci aşama anodik oksidasyon işlemine başlamadan önce, birinci aşama anodik oksidasyon işleminde oluşan oksit tabakası, yaklaşık 90 dakika boyunca $60{ }^{\circ} \mathrm{C}$ 'de kimyasal dağlama çözeltisi $(0,1 \mathrm{M}$ fosforik asit ve $0,1 \mathrm{M}$ kromik asit karışımı) yardımıyla uzaklaştırılmıştır.

İkinci aşama anodik oksidasyon işlemi, birinci aşama anodik oksidasyon ile aynı koşullarda $(0,3 \mathrm{M}$ oksalik asit çözeltisinde $40 \mathrm{~V}$ sabit gerilim değerinde) 60 dakika süreyle gerçekleştirilmiş̧ir. Bütün anodik oksidasyon deneyleri bilgisayar kontrolünde gerçekleştirilmiştir. Deneyi takip ve verileri almak için LabVIEW programı kullanılmıştır. Anodik oksidasyon işlemi sırasında akım yoğunluğu-süre grafikleri de çizdirilmiştir.

Çalışmamızda, gözenek çapını kontrol etmek için kimyasal dağlama işlemi, oda sıcaklığındaki $0,1 \mathrm{M}$ fosforik asit çözeltisinde farklı süreler kullanılarak gerçekleştirilmiştir. Kimyasal dağlama, gözenek düzenliliğinin arttırılmasını, işlem süresiyle kontrol eden bir mekanizmaya sahiptir. Bu bağlamda, çalışmada dağlama süresinin değiştirilmesiyle gözenek çapları kontrol edilmiştir. Kimyasal dağlama işlemi $30^{\circ} \mathrm{C}^{\prime}$ lik $0,1 \mathrm{M}$ fosforik asit çözeltisi içerisinde 0,30 ve 60 dakikalık süreler boyunca uygulanarak, farklı por büyüklüklerine sahip anodik oksit şablonların üretimi gerçekleşmiştir. Yapılan işlemlerin özetlendiği akış şeması Şekil 1'de gösterilmiştir.

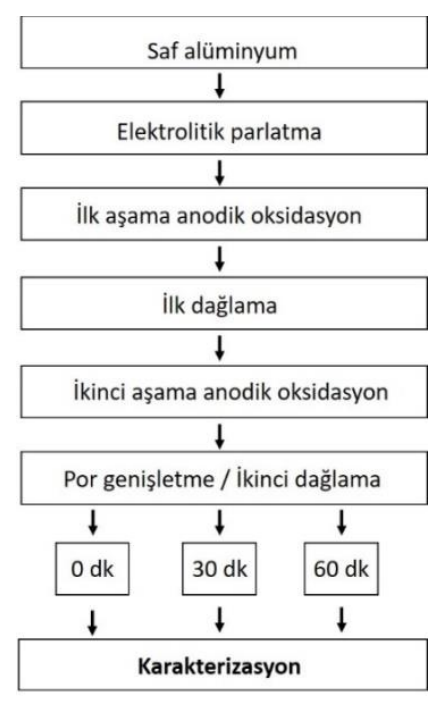

Şekil 1. Yapılan işlemlere ait aklş şeması 


\subsection{Karakterizasyon}

Por yapıları hakkında detaylı bilgiye sahip olmak için alan emisyonlu taramalı elektron mikroskobu Philips-XL30 FEG-SEM (FEI, Eindhoven, Hollanda) kullanılmıştır. İncelemeler öncesinde oksit yüzeyinin elektron iletkenliğine uygun olmaması ve elektron yüklenme etkisini ortadan kaldırmak için altın-paladyum karışımı ile birkaç dakika süresince kaplanmıştır. Yüzey görüntüleme işlemi için 10 ve $20 \mathrm{kV}$ hızlandırma voltajı kullanılmıştır. SEM ile numunelerin yüzey topografileri ikincil elektron ışınları yardımıyla incelenmiş ve anodik oksidasyon işlemi sonrası por çapları ölçülmüştür. Anodik oksidasyon işleminin en önemli değişkenlerinden biri de oksit por çaplarıdır. Por çaplarının ölçülmesinde birden fazla yöntem kullanılmaktadır. Bu yöntemlerden en yaygını yüzey görüntüsü ile gerçekleştirilen ölçümlerdir. Bu çalışmada ortalama por çaplarının ölçümü "imageJ" programı yardımı ile gerçekleştirilmiştir. Aynı koşula ait farklı yüzey görüntülerindeki en az 25 por kullanılarak ortalama por çapları hesaplanmıştır.

\section{Araştırma Sonuçları ve Tartışma}

\subsection{Akım Yoğunluğu-Zaman Davranışları}

Bu çalışmada, anodik oksidasyon sürecini daha iyi anlamak için ikinci anodik oksidasyona ait akım yoğunluğu - süre (I-t) grafiği Şekil 2'de gösterilmiştir. Akım yoğunluğu başlangıçta saf alüminyumun yüksek iletkenliğinden dolayı yüksek değerden başlamış, yüzeyde sıkı bariyer tip oksit tabakası oluştuğu için çok hızlı bir şekilde azalmıştır. Hızlı düşüşün ardından gelen hafif artış, bariyer tabakasının kalınlığında ki düşüşe neden olan gözenek derinliğindeki artıştan kaynaklanmaktadır. Son kısımda ise akım yoğunluğu, porların alüminyum yüzeyi boyunca yayılmaya başlamasıyla sabit bir değere ulaşmıştır. Gerçek akım yoğunluğu ve anodik oksidasyon zaman verileri, anodik oksidasyon sürecini dolayısıyla gözenek derinliğini ve gözenek geometrisini kontrol etmek/ayarlamak için kullanılmaktadır. Akımdaki düşüş oranı, önemli bir şekilde anodik fillmin düzgünlüğüne dayanır bu da yüzeyde biriktirilmiş metal katmanın pürüzlülüğüne bağlıdır. Çalışma sonunda elde edilen akım yoğunluğu - anodik oksidasyon süresi grafiği ile anodik oksidasyon işleminin arzu edilen bir şekilde gerçekleştiği tespit edilmiştir (Ma, 2010; Sheasby, P., \& Pinner, 2001; Sulka, 2008).

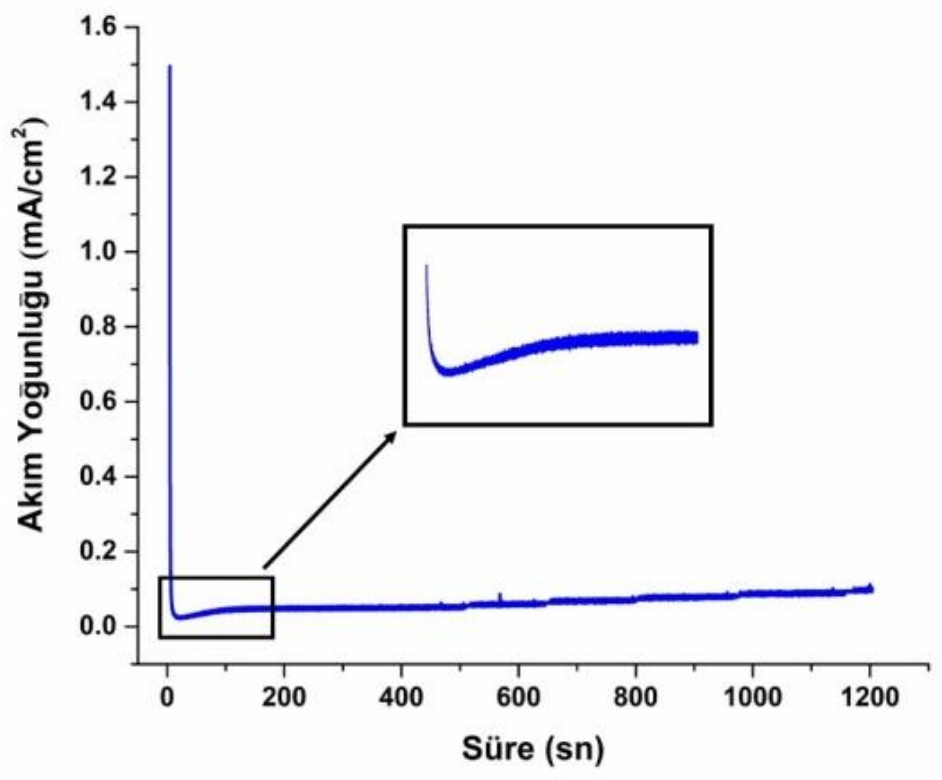

Şekil 2. Poröz filmin gelişsiminde farkl gerilim değerlerindeki deneylere ait akım yoğunluğu-süre grafikleri

\subsection{Mikroyapısal İncelemeler}

İlk aşama anodik oksidasyon işleminden sonra, Şekil 3 (a ve b)'de gösterildiği gibi porların şekilleri ve boyutları geniş bir dağılım aralığı göstermiştir. Burada alüminyum üzerindeki porlar, rastgele yönlendirilmiş bir şekilde düzensiz olarak oluşmuştur. Gözenekleri doğrudan aşağıdan yukarıya doğru dik bir şekilde üretmek ve düzenli olarak dağıtmak için ikinci aşama anodik oksidasyon işlemi gereklidir. 


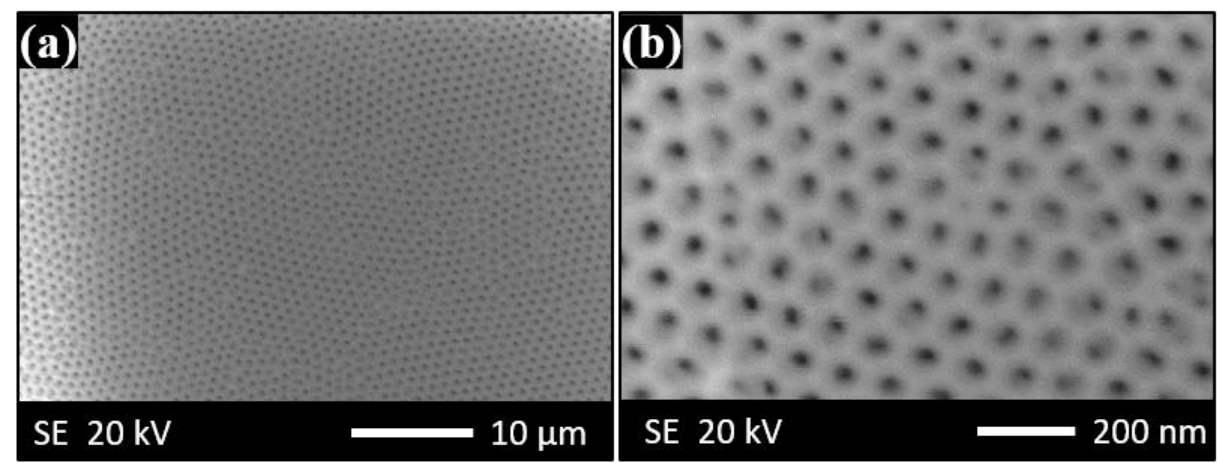

Şekil 3. Ilk aşama anodik oksidasyon işleminden (0,3 M oksalik asit, 10 saat) sonra oksit tabakasının farklı büyütmelerde yüzey SEM görüntüleri

Oksit film tabakasının numune yüzeyinden kimyasal dağlama yoluyla uzaklaştırılmasından sonra, ikinci aşama anodik oksidasyon için bir şablon olarak rol oynayan bal peteği yapılı desen, Şekil 4 (a ve b)'de gösterildiği gibi elde edilmiştir. Şekil 4'te görülen her altıgenin boyutu yaklaşık $100 \mathrm{~nm}$ ve derinlikleri ise yaklaşık $5 \mathrm{~nm}$ 'dir.
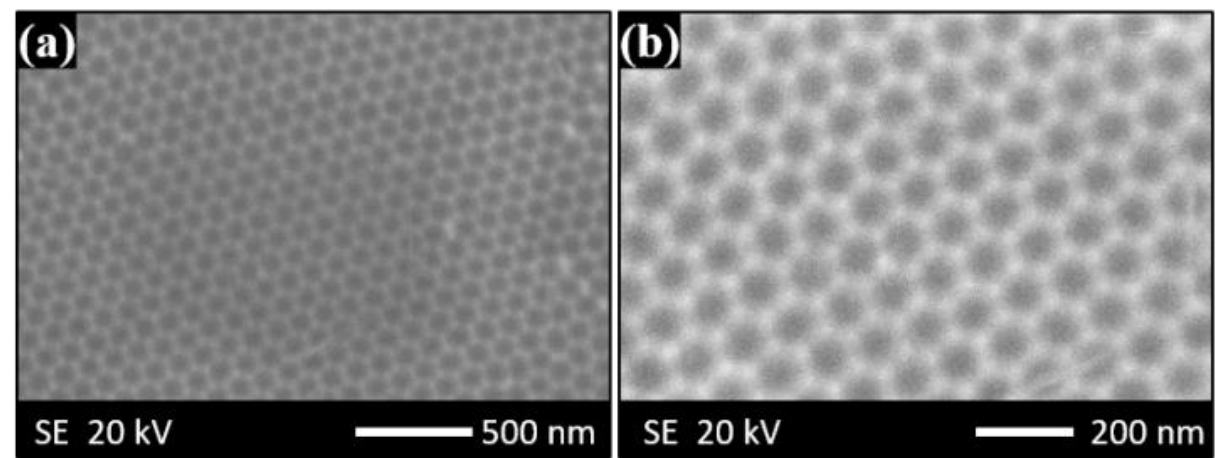

Şekil 4. İlk aşama anodik oksidasyon işleminin ardından uygulanan kimyasal dağlama ile elde altıgen desenin farklı büyütmelerde yüzey SEM görüntüleri.

İkinci aşama anodik oksidasyon işleminden sonra, farklı çaplara sahip düzgün altıgen ve iyi düzenlenmiş gözenekler, Şekil 5 (af)'de gösterildiği gibi oluşturulmuştur. Orijinal gözenek çap1 (por genişletme olmaksızın), Şekil 5 (a ve b)'de gösterildiği gibi yaklaşık $41 \pm 9$ nm'dir. Fosforik asit çözeltisinde 30 ve 60 dakika boyunca gözenek genişletme işleminden sonra, gözenek çapı sırasıyla $50 \pm 7$ $\mathrm{nm}$ ve $73 \pm 6$ nm'ye büyütülmüştür. Por genişletmenin amacı, por duvarlarının kalınlığını azaltarak por çaplarını büyütmektir. Şekil 4'ten de görüleceği üzere, por çapı ve duvarının ulaşabileceği maksimum genişlik $100 \mathrm{~nm}$ olabileceği için 60 dakikadan daha uzun süreli por genişletme işlemi por yapısına zarar vereceği için uygun değildir. Por genişletme süresine bağlı olarak por değişimleri Şekil 6'daki grafikte gösterilmiştir. Şekil 5 ve 6'dan görüleceği üzere por genişletme işlem süresinin artmasıyla oksit porların homejenliği ve dairesellik değerleri artmıştır. Artan işlem süresiyle tespit edilen bu durum Ersching ve ark. (Ersching et al., 2012) yaptıkları çalışmada da doğrulanmıştır. 

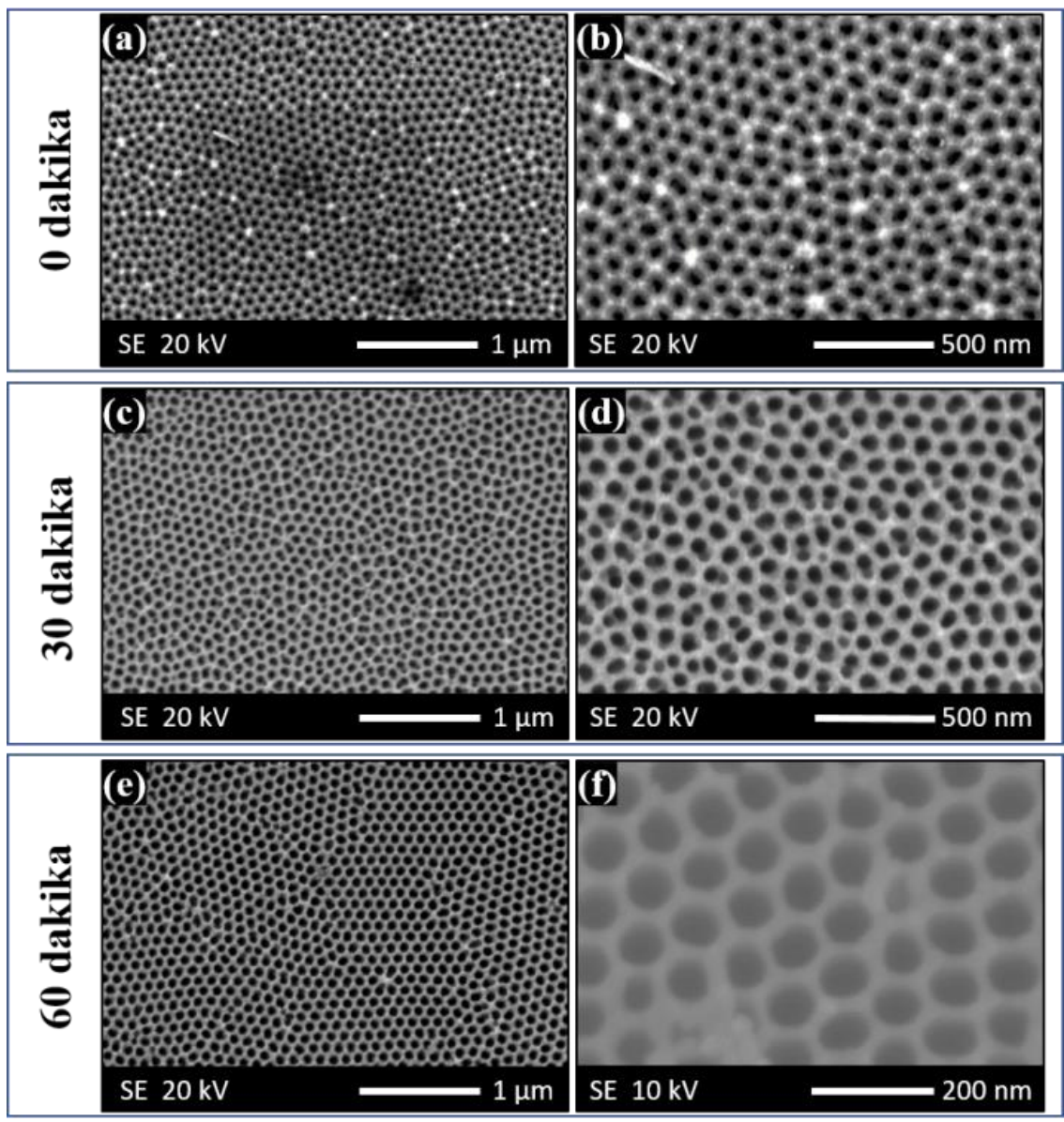

Şekil 5. İkinci anodik oksidasyon işleminden sonra oksit filmin yüzey farklı büyütmelerde SEM görüntüleri (a-b) Por genişletme yapılmadan (c-d) 30 dakika por genişletme (e-f) 60 dakika por genişletme

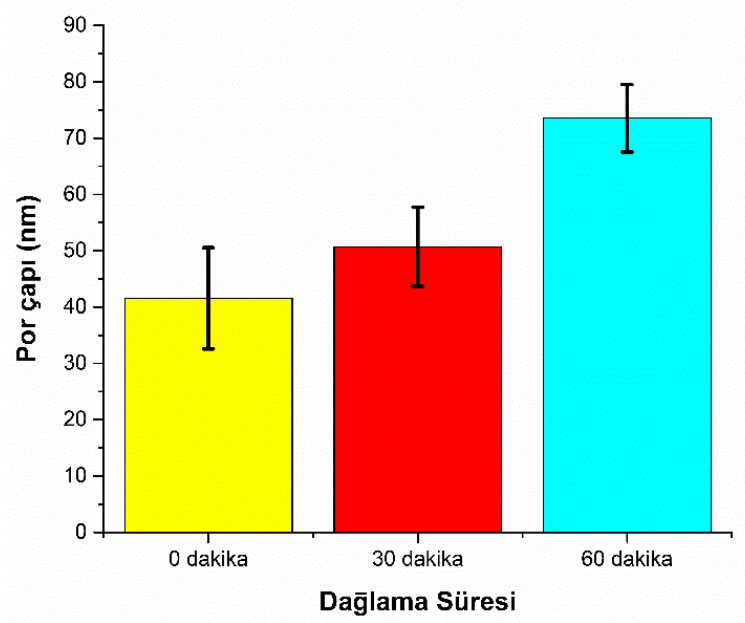

Şekil 6. Por genişletme süresine bağll olarak ortalama por çaplarının değişimleri

\section{Sonuç}

Bu çalışmada saf alüminyum yüzeyinde gerçekleştirilen iki aşamalı anodik oksidasyon işlemi başarıyla gerçekleştirilmiş olup, iki aşamalı işlem sonunda orijinal ortalama gözenek çapı yaklaşık $41 \pm 9 \mathrm{~nm}$ olarak hesaplanmıştır. 30 ve 60 dakika boyunca gerçekleştirilen por genişletme işlemi por duvarlarının kalınlığını azaltarak por çaplarını büyümesine olanak sağlamıştır. Gözenek çapları 30 ve 60 dakikalık genişletme işleminden sonra sırasıyla $50 \pm 7 \mathrm{~nm}$ ve $73 \pm 6 \mathrm{~nm}$ olarak hesaplanıştır. Por genişletme işlemi por çapını genişletmesinin yanı sıra daha düzenli bal peteği yapısına ulaşılmasına neden olmuştur. Farklı büyüklüklere sahip nanotellerin/tüplerin üretiminde arzu edilen bu durum sayesinde daha düzgün ve homojen nanoyapıların üretimi gerçekleştirilebilecek ve bu malzemelerin mekanik testleri sonucunda boyut etkisi üzerine çalışmalar yürütülmesine olanak sağlanacaktır. 


\section{Kaynakça}

Bouchama, L., Azzouz, N., Boukmouche, N., Chopart, J. P., Daltin, a. L., \& Bouznit, Y. (2013). Enhancing aluminum corrosion resistance by two-step anodizing process. Surface and Coatings Technology, 235, 676-684. https://doi.org/10.1016/j.surfcoat.2013.08.046

Diggle, J., Downie, T., \& Goulding, C. (1969). Anodic oxide films on aluminum. Chemical Reviews, 66(3), 365. https://doi.org/10.1021/cr60259a005

Dimiduk, D. M., Uchic, M. D., \& Parthasarathy, T. A. (2005). Size-affected single-slip behavior of pure nickel microcrystals. Acta Materialia, 53(15), 4065-4077. https://doi.org/10.1016/j.actamat.2005.05.023

Erdogan, P., Yuksel, B., \& Birol, Y. (2012). Effect of chemical etching on the morphology of anodic aluminum oxides in the two-step anodization process. Applied Surface Science, 258(10), 4544-4550. https://doi.org/10.1016/j.apsusc.2012.01.025

Ersching, K., Dorico, E., Da Silva, R. C., Zoldan, V. C., Isoppo, E. a., Viegas, a. D. C., \& Pasa, a. a. (2012). Surface and interface characterization of nanoporous alumina templates produced in oxalic acid and submitted to etching procedures. Materials Chemistry and Physics, 137(1), 140-146. https://doi.org/10.1016/j.matchemphys.2012.08.058

Greer, J. R., \& De Hosson, J. T. M. (2011). Plasticity in small-sized metallic systems: Intrinsic versus extrinsic size effect. Progress in Materials Science, 56(6), 654-724. https://doi.org/10.1016/j.pmatsci.2011.01.005

Greer, J. R., Oliver, W. C., \& Nix, W. D. (2005). Size dependence of mechanical properties of gold at the micron scale in the absence of strain gradients. Acta Materialia, 53(6), 1821-1830. https://doi.org/10.1016/j.actamat.2004.12.031

Han, X. Y., \& Shen, W. Z. (2011). Improved two-step anodization technique for ordered porous anodic aluminum membranes. Journal of Electroanalytical Chemistry, 655(1), 56-64. https://doi.org/10.1016/j.jelechem.2011.02.008

Iglesias-Rubianes, L., Skeldon, P., Thompson, G. E., Shimizu, K., \& Habazaki, H. (2001). Influence of current density in anodizing of an Al-W alloy. Corrosion Science, 43(12), 2217-2227. https://doi.org/10.1016/S0010-938X(01)00022-1

Ilango, M. S., Mutalikdesai, A., \& Ramasesha, S. K. (2016). Anodization of Aluminium using a fast two-step process. Journal of Chemical Sciences, 128(1), 153-158. https://doi.org/10.1007/s12039-015-1006-8

Kiener, D., Motz, C., Schöbert, T., Jenko, M., \& Dehm, G. (2006). Determination of mechanical properties of copper at the micron scale. Advanced Engineering Materials, 8(11), 1119-1125. https://doi.org/10.1002/adem.200600129

Konno, H., Utaka, K., \& Furuichi, R. (1996). A two step anodizing process of aluminium as a means for improving the chemical and physical properties of oxide films. Corrosion Science, 38(12), 2247-2256. https://doi.org/10.1016/S0010-938X(97)83145-9

Li, A. P., Müller, F., Birner, A., Nielsch, K., \& Gösele, U. (1999). Polycrystalline nanopore arrays with hexagonal ordering on aluminum. Journal of Vacuum Science \& Technology A: Vacuum, Surfaces, and Films, 17(4), 1428-1431. https://doi.org/10.1116/1.581832

Liu, Y.-F., Wang, F.-H., Guo, D.-L., Huang, S.-Y., Sang, J.-P., \& Zou, X.-W. (2009). Effects of heat treatment on optical absorption properties of Ni-P/AAO nano-array composite structure. Applied Physics A, 97(3), 677-681. https://doi.org/10.1007/s00339-0095289-9

Ma, Y. (2010). Effect of Microstructure on corrosion resistance and anodising behaviour of AA 2099-T8 aluminium alloy, 1-311.

Masuda, H., \& Fukuda, K. (1995). Ordered Metal Nanohole Arrays Made by a Two-Step Replication of Honeycomb Structuresof Anodic Alumina. Science, 268(5216), 1466-1468. https://doi.org/10.1126/science.268.5216.1466

Moldovan, V., Bruj, E., \& Jumate, N. (2011). Porous anodic alumina films obtained by two step anodization. Bulletin of the Transilvania University of Braşov Series I: Engineering Sciences, 4(2), 75-80. https://doi.org/10.1007/s10008-011-1471-z

Montero-Moreno, J. M., Sarret, M., \& Müller, C. (2007). Influence of the aluminum surface on the final results of a two-step anodizing. Surface and Coatings Technology, 201, 6352-6357. https://doi.org/10.1016/j.surfcoat.2006.12.003

Montero-Moreno, J. M., Sarret, M., \& Müller, C. (2007). Some Considerations on the Influence of Voltage in Potentiostatic Two-Step Anodizing of AA1050. Journal of The Electrochemical Society, 154(3), 169-174. https://doi.org/10.1149/1.2426880

Ng, K. S., \& Ngan, A. H. W. (2008). Stochastic nature of plasticity of aluminum micro-pillars. Acta Materialia, 56(8), 1712-1720. https://doi.org/10.1016/j.actamat.2007.12.016

Sheasby, P., \& Pinner, R. (2001). The surface treatment and finishing of aluminium and its alloys.

Stelmashenko, N. A., Walls, M. G., Brown, L. M., \& Milman, Y. V. (1993). Microindentations on W and Mo oriented single crystals: An STM study. Acta Metallurgica Et Materialia, 41(10), 2855-2865. https://doi.org/10.1016/0956-7151(93)90100-7

Sulka, G. D. (2008). Highly Ordered Anodic Porous Alumina Formation by Self-Organized Anodizing. In Nanostructured Materials in Electrochemistry (pp. 1-116). https://doi.org/10.1002/9783527621507.ch1

Thompson, G., Xu, Y., \& Skeldon, P. (1987). Anodic oxidation of aluminium. Philosophical Magazine Part B, 55(6), 651-667. https://doi.org/10.1080/13642818708218371

Uchic, M. D., Dimiduk, D. M., Florando, J. N., \& Nix, W. D. (2004). Sample dimensions influence strength and crystal plasticity. Science, 305(5686), 986-989. https://doi.org/10.1126/science.1098993

Zaraska, L., Sulka, G. D., \& Jaskuła, M. (2010). The effect of n-alcohols on porous anodic alumina formed by self-organized two-step anodizing of aluminum in phosphoric acid. Surface and Coatings Technology, 204(11), 1729-1737. https://doi.org/10.1016/j.surfcoat.2009.10.051

Zaraska, L., Sulka, G. D., \& Jaskuła, M. (2011). Anodic alumina membranes with defined pore diameters and thicknesses obtained by adjusting the anodizing duration and pore opening/widening time. Journal of Solid State Electrochemistry, 15(11-12), 24272436. https://doi.org/10.1007/s10008-011-1471-Z

Zhou, J. H., He, J. P., Zhao, G. W., Zhang, C. X., Zhao, J. S., \& Hu, H. P. (2007). Alumina nanostructures prepared by two-step anodization process. Transactions of Nonferrous Metals Society of China (English Edition), 17(1), 82-86. https://doi.org/10.1016/S1003-6326(07)60052-1. 